\title{
Plant invasion correlation with climate anomaly: an Indian retrospect
}

\author{
Poonam Tripathi ${ }^{1,2} \cdot$ Mukunda Dev Behera ${ }^{2} \cdot$ Partha Sarathi Roy $^{3}$
}

Received: 18 December 2018 / Accepted: 2 February 2019 / Published online: 9 February 2019

(c) Springer Nature B.V. 2019

\begin{abstract}
Plant invasion is highly responsive to rising temperature, altered precipitation and various anthropogenic disturbances. Therefore, climate anomalies might provide opportunities to identify the relationship of past climate in deriving the distribution of invasive species and to detect their probable future distribution. In this work, we studied the correlation of climate anomaly i.e. temperature and precipitation with an indicative map of plant invasive species $\left(1^{\circ}\right.$ grid) of India. The indicative map was generated through the plant data available from the project 'Biodiversity Characterization at Landscape Level'. Climate anomaly was calculated and represented by average temperature and precipitation using 'Climate Research Unit' data for the period of 1901 to 2000. A comparison of local geographically weighted regression (GWR) model and a global ordinary least square regression (OLS) model was carried out for statistical analysis to depict the correlation at $1^{\circ}$ spatial grids. Overall, 20,501 records with a total of 9112 unique plots and 161 unique invasive species were recorded in the database that shows a maximum of 15 invasive species in a 0.04 ha nested quadrat. Cumulative analysis showed a maximum of 53 invasive species at $1^{\circ}$ grid. Individually, GWR could reveal a significant correlation with invasive species distribution for temperature anomaly $\left(\mathrm{r}^{2}=0.73, \mathrm{AIC}=2206\right)$ and precipitation anomaly $\left(\mathrm{r}^{2}=0.74\right.$, AIC $=2221)$, while OLS model did not offer a good correlation $\left(r^{2}<0.001\right.$, AIC $\left.>2400\right)$ compared to GWR. Combination of temperature and precipitation anomaly (shared model) showed an improved spatial correlation $\left(r^{2}>0.75\right)$ using GWR. Variation partitioning revealed the dominant influence ( $>0.40$ of variation) of temperature anomaly over Deccan Peninsula, Himalaya and North East zone. Influence of precipitation anomaly was more prominent over arid and semi-arid zone explaining $>0.35$ of variation. Results revealed the strength of GWR to see the interaction of invasive plant species w.r.t. climate anomalies that explain the influence of spatial variation due to heterogeneity at varying neighbour distances. The significant correlation of invasive species with both the anomalies revealed the affinity of invasive species towards warmer, drier and wet places. This gives an indication that the distribution of invasive species could be triggered by climate anomaly. The use of
\end{abstract}

Communicated by M. D. Behera, S. K. Behera and S. Sharma.

Electronic supplementary material The online version of this article (https://doi.org/10.1007/s1053 1-019-01711-0) contains supplementary material, which is available to authorized users.

Extended author information available on the last page of the article 
other predictor variables (i.e. edaphic and anthropogenic) could be an inclusive input in a future perspective.

Keywords Climate change $\cdot$ Anomaly $\cdot$ Invasive species $\cdot$ GWR $\cdot$ OLS $\cdot$ India

\section{Introduction}

Climate change and invasion are two main global threats to biodiversity and ecosystem services (Vitousek et al. 1996; Nentwig 2007; Maclean and Wilson 2012). Invasive species have been defined by Kolar and Lodge (2001) as 'a non-indigenous species that spreads from the point of introduction and becomes abundant'. Plant invasion is highly responsive to rising temperature, altered precipitation and various anthropogenic disturbances that subsequently favor the distribution and number of invasive species (Easterling et al. 2000; Hellmann et al. 2008; Walther et al. 2009). Studies have shown major influence of climate change on occurrences of invasive species as they possess advanced traits of sexual and asexual reproduction, rapid growth, high tolerance to environmental heterogeneity and the adaptation to environmental stress (phenotypic plasticity) and, better resource use efficiencies i.e. light, nutrient, water and carbon (Baker 1965, 1974; Visser 2008; Seastedt and Pyšek 2011; Kimball et al. 2014). The broader climate tolerance range of invasive species than natives provides them suitable habitats under the impact of climate change (Walther et al. 2009). For example, a shift in temperature, precipitation, and $\mathrm{CO}_{2}$ range might have a little impact on invasive species compared to natives by altering the competitive dynamics for available resources and spatial variation (Cox and Ruyle 1986; Richardson et al. 2000). A recent study by Pantoja et al. (2018) found the ability of invasive species to adapt to new environments which suggests that the behaviour of invasive plants changes over time.

Therefore, knowledge of the current establishment and relationship of invasive species with climate is critical to assess environmental impacts, economic costs, and ecosystem management for a comprehensive understanding of their interaction with future climate change (Khuroo et al. 2007; Thapa et al. 2018). Climate anomalies in this perspective may provide opportunities for detecting invasive species from local to global scale using various advanced technologies including remote sensing based platform.

Climate anomalies can be described as the substantial and rapid deviation of a particular variable (i.e. temperature, precipitation) from the mean in intensity, quantity, type, temporal and spatial distribution (Rosenzweig et al. 2000). Climate change influences the ecosystem by altering species' interactions, population demography, germination, recruitment, establishment, and distribution. On the other hand, invasive species influence the magnitude, rate, and impact of climate change by altering ecosystem functioning, structure, and composition (Pyšek and Richardson 2010; Smith et al. 2012). Therefore, under climate change, the impacts of invasive species might get worse for existing natives by exacerbating environmental stress such as water availability (Compagnoni and Adler 2014; Kumschick et al. 2015; Rumlerova' et al. 2016). For example, White et al. (2001) studied an altered competitive interaction between $\mathrm{C} 3$ and $\mathrm{C} 4$ species due to an extreme heating event. Asner et al. (2006) observed a faster growth rate of invasive species compared to a native species under very harsh climate in Hawaiian rain forests.

India is likely to be prone to plant invasions due to several historical and geographical factors (IndianStat 2017). Many natural and anthropogenic activities have created migration routes facilitating the invasive window and causing ecological and economic damage 
to the native biodiversity in India (Inderjit 2005). Various invasive species of India have been compiled for different regions (Sharma and Pandey 1984; Pandey and Parmar 1994; Nagar et al. 2004; Khuroo et al. 2012). Introduction of these has posed a serious threat to natives (Kohli et al. 2004; Sharma et al. 2005) by naturalizing the ecosystem or by removing the entire native plant community (Dogra et al. 2009; Kannan et al. 2013; Inderjit et al. 2017). A review by Sajeev et al. (2012) discusses the threat of invasive species to natural forests of the Kerala state of India where they identified 38 high impacting invasive species in the forests of Kerala through a risk assessment protocol. Studies predict the wide distribution of invasive species under future climatic scenarios (Majumdar and Karthikeyan 1989; Adhikari et al. 2015; Panda et al. 2018). Future prediction of invasive species by Barik and Adhikari (2012) have estimated the potential future distribution of Cromolaena odorata due to climate change over Indian sub-continent for A2 and B2 scenarios for 2020 and 2080 respectively using HADCAM3 model. Recently Panda et al. (2018) demonstrated the probable distribution of two invasive species i.e. Lantana camara and Cassia tora towards northern and north-eastern directions in India, owing to changes in moisture availability. Therefore, to study the future distribution of invasive species it is necessary to identify the relationship of past climate in deriving their distribution.

A substantial number of studies have shown that species-environment relationships always emerge with complex features, for example, non-linearity, and non-stationarity, especially in the highly heterogeneous regions (Beale et al. 2007; Latimer et al. 2009; Gao et al. 2012; Zhao et al. 2015). However, linear regression analyses of the global perspective, which assumes the correlation to be spatially constant, were used to explore these relationships due to computational limitations of spatially explicit models for large datasets (Banerjee et al. 2004). Recently, geographically weighted regression (GWR), which is an extension of traditional standard global regression techniques, was developed to explore spatially varying relationships (Fotheringham et al. 2002). A few studies have confirmed the analytical efficacy of GWR for investigating spatially varying relationships between plant species and environmental variables (Shrestha 2006; Eiserhardt et al. 2011; MartínQueller et al. 2011; Xu et al. 2016). However, to our knowledge, no studies have focused on the spatial influence of climate anomaly variables on invasive species in India.

There has been a rapid advancement in geo-processing tools leading to the generation of digital data. However, a tremendous variety of these datasets owing to different collection method, spatial resolutions, sensors, and models could pose a bias in interpreting the ecological information. Therefore, to make use of this available information, the various data sets have to be linked explicitly by integrating into one uniform data set. In this work, we aim to model the relationship between the invasive plant richness and climate anomaly (i.e. temperature and precipitation) in India at $1^{\circ}$ grid level by comparing a global model i.e. ordinary least square regression (OLS) with a local model (GWR).

\section{Materials and methods}

India lies between latitudes of $6^{\circ} 44^{\prime}$ and $35^{\circ} 30^{\prime} \mathrm{N}$ and longitudes of $68^{\circ} 7^{\prime}$ and $97^{\circ} 25^{\prime} \mathrm{E}$ covering an overall geographical area of nearly 329 million hectares (Fig. 1). The climate is categorised to four major monsoonal periods as (i) warm and humid southwest summer monsoon (June-August), (ii) cold and dry north-east winter monsoon (December-February), (iii) spring (March-May) and (iv) autumn (September-November). Most of the annual rainfall $(80 \%)$ is received during the south-west summer monsoon. The large spatial 

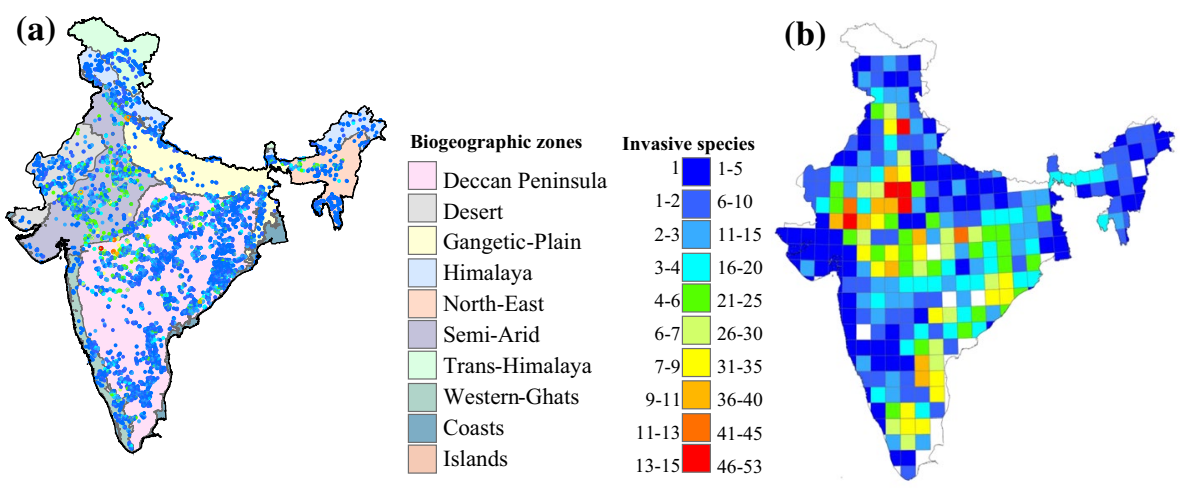

Fig. 1 Indicative maps of Invasive species distribution in India a enumerated in a 0.04 ha nested quadrats, (maximum is 15 ); $\mathbf{b}$ Represented at $1^{\circ} \times 1^{\circ}$ grids (Maximum is 53)

variability in monsoonal activity has accounted for diverse eco-regions with a wide range of vegetation types owing to wide ranges of 10 bio-geographic zones with distinctive ecology, biomes, communities, and species (Rodgers and Panwar 1988).

\section{Invasive species data}

In this study, we used the species data collected through the project 'Indian National-Level Biodiversity Characterization at Landscape Level' (Roy et al. 2015). In this project, 15,565 nested quadrats of area 0.04 ha were laid in 100 vegetation types across the length and breadth of the country. The sites were selected on the basis of stratified random sampling (Roy et al. 2015; Fig. 1a). The field sampling was dominantly conducted in post-rainy seasons, thereby accommodating most of the invasive species. From the above-mentioned data, an indicative invasive plant species data was generated. For the purpose, a fishnet of $1^{\circ}$ grid size covering the whole study area was created using the 'Create Fishnet' tool of ArcGIS 9.3. The counts of unique invasive plant species were spatially appended to the respective grid cells using the spatial join method (Fig. 1b). Invasive species were identified based on the online database on alien species available via ENVIS Centre, Ministry of Environment, Forest and Climate Change (MOEFCC) Government of India. These species were then classified based on their families and life form. The grids with no sampling and no invasive species were not considered in the analysis.

\section{Correlation of invasive species with climate anomaly}

\section{Climate data}

The temperature and precipitation data were used to derive anomalies from 100 years datasets (1901-2000) to study the long-term climatology. The data were obtained from climatic products of Climatic Research Unit (CRU) at $0.5^{\circ} \times 0.5^{\circ}$ resolution. New et al. (1999) derived these data from monthly terrestrial surface climate variables for the period from 1901 to 1998 (CRU TS 1.0) and updated to 2000 (CRU TS 1.1). Mitchell and Jones 
(2005) revised these grids and updated them to 2000 (CRU TS 2.0). These datasets hold time series of five climatic variables (i.e., cloud cover, DTR, precipitation, temperature and vapour pressure deficit) from several thousand terrestrial-based stations worldwide. The open-source GIS software GRASS (Geographic Resources Analytical Support System) was used on Linux operating system to convert the CRU datasets into GRASS raster data layers. GRASS GIS modules along with Linux scripting were used to extract the monthly average rainfall and average temperatures from 1901 to 2000. Climate anomaly was calculated using MATLAB software.

\section{Anomaly derivation}

To derive climate anomalies we have used mean based difference measures. For anomaly construction, we need to split data into two parts as (i) data with expected behaviour and (ii) data that shows variability from the expected. Here, the monthly mean values of temperature and precipitation were considered as the base showing the data with expected behaviour and these base values were subtracted from the individual raw data, which is a measure of deviation from expected. Therefore, for a given location i, its anomaly time series f'i constructed from the raw time series $f$ i by removing a base vector $f$ from it by following Kawale et al.(2011) and New et al. (1999) and given as:

$$
f^{\prime} \mathrm{i}=f \mathrm{i}-(\overline{f i}),
$$

where $f^{\prime} i$ represents the climate anomaly (deviation from the expected). $f$ i is the individual raw data for a particular location and $(\overline{f i})$ is the base vector (represents the monthly mean values).

\section{Global versus local models}

We performed global (OLS) and local (GWR) regression analysis for each set of variables to account the spatial variation in the invasive species-climate anomaly relationships. Regression model relies on determining the dependent variable (y) by producing a minimum sum of squares $y$ with regard to the independent variable, $x$. However, GWR is an extension of OLS which calibrates multiple regressions and fits them at each sample point. This approach allows all regression statistics such as partial slopes and the coefficient of determination $\left(r^{2}\right)$ to be calculated at each focal cell (Fotheringham et al. 2002). An adaptive bi-square spatial kernel weighting function was implemented to avoid large local estimation variance in areas where data are sparse. The regression equation is can be summarised as:

$$
\mathrm{Yi}=\beta_{0}\left(\mathrm{u}_{\mathrm{i}} \mathrm{v}_{\mathrm{i}}\right)+\sum_{\mathrm{j}=1}^{\mathrm{k}}\left(\mathrm{x}_{\mathrm{ij}} \beta_{\mathrm{j}}\left(\mathrm{u}_{\mathrm{i}}, \mathrm{v}_{\mathrm{i}}\right)+\varepsilon_{\mathrm{i}}\right)(3),
$$

where $\mathrm{j}=1$, $\mathrm{k}$ explanatory variables, $\varepsilon_{\mathrm{i}}$ is a random error term and the location for each observation is defined by the coordinates $\left(\mathrm{u}_{\mathrm{i}}, \mathrm{v}_{\mathrm{i}}\right) . \beta_{0}-\beta_{\mathrm{k}}$ are the parameters of the model with $\beta_{\mathrm{j}}\left(\mathrm{u}_{\mathrm{i}}, \mathrm{v}_{\mathrm{i}}\right)$ a realization of the continuous function $\beta_{\mathrm{j}}\left(\mathrm{u}_{\mathrm{i}}, \mathrm{v}_{\mathrm{i}}\right)$ at location $\mathrm{i}$.

The corrected Akaike information criterion (AICc) was used to compare the performance of OLS with GWR-based outputs. We analysed four neighbours at $5 \%$ increments, from 5 to $20 \%$, to capture the spatial variation using adaptive bi-square kernel function. We computed local $\mathrm{r}^{2}$ values separately and in combination (shared model), 
where the $r^{2}$ values represent the local variation fraction in invasive species richness. For each grid cell, we performed variation partitioning to determine the variation, which is individually explained by the precipitation and temperature anomaly, using the Spatial Analyses in Macroecology (SAM) software package (Rangel et al. 2010).

\section{Results}

\section{Invasive species pattern}

The inventory comprises of 20,501 records with a total of 9112 unique plots and 161 unique invasive species for India, falling under 83 vegetation types out of 100 described by Roy et al. (2015). The 161 unique invasive species belongs to 37 unique families owing to four life forms as herb, shrub, tree and climber (Table S1). The five most species-rich families are Asteraceae (29 spp.), Fabaceae (22 spp.), Convolvulaceae (13 spp.), Amaranthaceae (12 spp.) and Solanaceae (10 spp.) respectively (Table S1) from the present study. The maximum number of invasive species (15) at quadrat level was observed to be in Deccan peninsula zone followed by arid and semi-arid zone, 12; Gangetic plain,12; The Western Ghats, 9; northeast, 7 and; Himalaya and trans-Himalaya zone,6 (Fig. 1a). This range differed at $1^{\circ}$ grid level where maximum numbers were observed to be in the arid and semi-arid zone as 53 followed by Deccan peninsula, 44; the Western Ghats, 27; northeast, 19; Gangetic plain, 20 and; Himalaya and TransHimalaya, 13 respectively (Fig. 1b).

\section{Climate anomaly}

The spatial distribution of Temperature and Precipitation anomaly showed a gradual loss of spatial autocorrelation at higher distances (Fig. S1). The Moran's index showed a range of -0.137 to 0.56 for temperature anomaly and -0.233 to 0.624 for precipitation anomaly respectively. The positive autocorrelation was observed up to the distances of $\sim 500 \mathrm{~km}$ for temperature anomaly and $\sim 600 \mathrm{~km}$ for precipitation anomaly respectively, which at higher distances becomes negative depicting the spatial heterogeneity. The overall range of temperature anomaly (Fig. 2a) lies between a minimum of $-0.29{ }^{\circ} \mathrm{C}$ to a maximum of $1.36{ }^{\circ} \mathrm{C}$ and precipitation anomaly ranged between a minimum of $-381 \mathrm{~mm}$ to a maximum of $186 \mathrm{~mm}$ where negative sign depicts decrease and vice versa (Fig. 2b). Zone wise differences in anomaly were evident demonstrating an overall decrease in precipitation and an increase in temperature. At $1^{\circ}$ grid level, temperature and precipitation anomaly range varied from -0.18 to $0.86{ }^{\circ} \mathrm{C}$ and -381 to $186 \mathrm{~mm}$ in Deccan peninsula, -0.13 to $0.83{ }^{\circ} \mathrm{C}$ and -236 to $48 \mathrm{~mm}$ in arid and semi-arid, -0.06 to $1{ }^{\circ} \mathrm{C}$ and -67 to $-326 \mathrm{~mm}$ in Gangetic plain, -0.22 to 0.29 and -144 to $38.5 \mathrm{~mm}$ in northeast, -0.29 to $1.36{ }^{\circ} \mathrm{C}$ and -225 to $36 \mathrm{~mm}$ in Himalaya and trans-Himalaya and, -0.30 to $0.58{ }^{\circ} \mathrm{C}$ and -308 to $86.5 \mathrm{~mm}$ in western Ghats zone respectively (Fig. 2a, b). In the Gangetic plain zone, all the grids (100\%) showed loss of precipitation wherein, $97 \%$ of grids displayed loss of $>100 \mathrm{~mm}$; while $97 \%$ grids showed an increase in temperature with $>50 \%$ of grids displaying an increase of $>0.5{ }^{\circ} \mathrm{C}$ within the past century. 

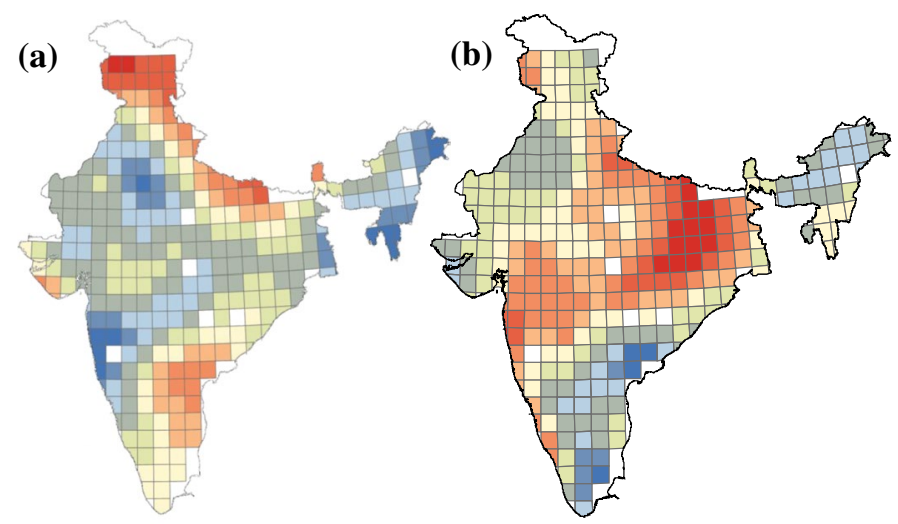

\begin{tabular}{|c|c|}
\hline Tanom & Panom \\
\hline$-0.29--0.12$ & $100-186$ \\
\hline$-0.12-0.00$ & $50-100$ \\
\hline $0.00-0.15$ & $0.00-50$ \\
\hline $0.15-0.30$ & $-50-0.00$ \\
\hline $0.30-0.45$ & $-100--50$ \\
\hline $0.45-0.60$ & $-150--100$ \\
\hline $0.60-0.75$ & $-200--150$ \\
\hline $0.75-0.90$ & $-250--200$ \\
\hline $0.90-1.30$ & $-300--250$ \\
\hline $1.30-1.36$ & $-381--306$ \\
\hline
\end{tabular}

Fig. 2 Spatial variation of climate anomaly at $1^{\circ}$ showing a temperature. b Precipitation

\section{Spatial correlation of invasive species with climate anomaly}

We assessed the accumulation of invasive species in different regions and the influence of climate anomaly using two models (OLS and GWR). A significant correlation (least AIC and highest $\mathrm{r}^{2}$ ) was observed between invasive species and climate anomaly for GWR at $5 \%$ of neighbours. The local $\mathrm{r}^{2}$ values favoured clear spatial heterogeneity between invasive species and climate anomaly in India. GWR models showed better model fits than OLS for all the combinations (Table 1). Highest coefficient of determination $\left(r^{2}=0.76\right.$, $\mathrm{AIC}=2259.7$ ) was observed when both the anomalies (i.e temperature and precipitation) were plotted together against invasive species (Table 1). The scatter plot of observed against estimated invasive species is shown in Fig. S2a. Individually, GWR could reveal a significant correlation with invasive species distribution for temperature anomaly $\left(r^{2}=0.73\right.$, $\mathrm{AIC}=2206)$ and precipitation anomaly $\left(\mathrm{r}^{2}=0.74\right.$, AIC $\left.=2221\right)$, while OLS model did not offer a good correlation $\left(\mathrm{r}^{2}<0.001\right.$, AIC $>2400$; Table 1$)$. This was further supported by residual analysis that showed less spatial autocorrelation of residuals for GWR at various spatial distances (Fig. 3). In contrast, residuals of OLS showed high autocorrelation reaching up 0.3 Moran's Index at shorter distances. The plotted boxplot of estimated vs. observed invasive species showed quite a disparity between GWR and OLS. It was clearly

Table 1 Statistical analysis for GWR vs. OLS showing correlation

\begin{tabular}{llllll}
\hline & \multicolumn{2}{l}{ OLS } & & & \multicolumn{2}{l}{ GWR } \\
\cline { 2 - 3 } \cline { 5 - 6 } & $\mathrm{R}^{2}$ & AICc & & $\mathrm{R}^{2}$ & AICc \\
\hline Variables & & & & \\
Temperature anomaly & $<0.001$ & 2413.9 & & 0.73 & 2206.18 \\
$\begin{array}{l}\text { Precipitation anomaly } \\
\text { Temperature, precipita- } \\
\text { tion anomaly }\end{array}$ & $<0.001$ & 2413.91 & 0.74 & 2221.43 \\
\hline
\end{tabular}

Significant results only at $5 \%$ of neighbours are displayed that depicted least AICc (Akaike information criteria)

$O L S$ ordinary least square, GWR geographically weighted regression 


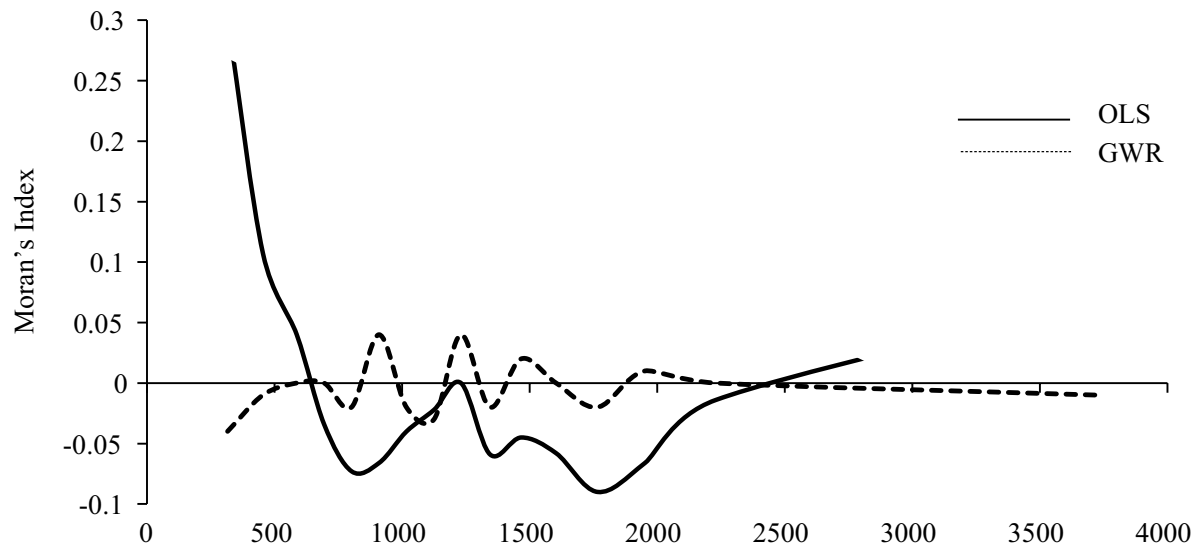

Fig. 3 Spatial correlogram of residuals for GWR and OLS for the combination of temperature and precipitation anomaly

revealed that GWR was superior over OLS, which could barely match the predicted data range of observed invasive species and accumulated in a narrow range (Fig. S2b).

Spatial variation showed an overall influence of both the anomalies for the distribution of invasive species in India, where the combination of temperature and precipitation showed spatial $\mathrm{r}^{2}$ value range between 0 and 0.87 . Individually, temperature anomaly could explain the spatial correlation range between 0 and 0.81 and precipitation anomaly between 0 and 0.84 respectively. Highest spatial correlation ( $>0.70$ of variation) was observed in arid and semi-arid zone for the combination of temperature and precipitation anomaly (Fig. 4a) accommodating Rajasthan and Punjab states of India.

To see the individual effect of variables and to explore the relationship of invasive species with climate anomaly a variation partitioning was carried out (Fig. 4b, c). Variation partitioning revealed the dominant influence of temperature anomaly ( $>40 \%$ of variation) over Himalaya, Deccan Peninsula, and northeast zone accommodating Himachal Pradesh, Madhya Pradesh, Odisha, Andhra Pradesh states respectively. Least correlation was observed in the trans-Himalaya and Western Ghats zone accommodating Arunachal Pradesh, Kerala and Karnataka state respectively. Precipitation anomaly was more

(a)

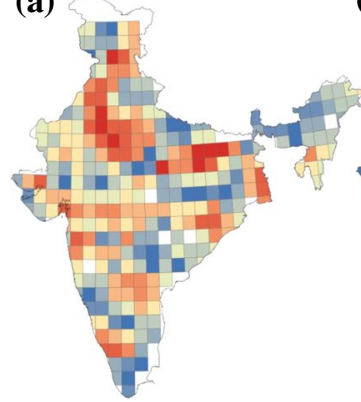

(b)

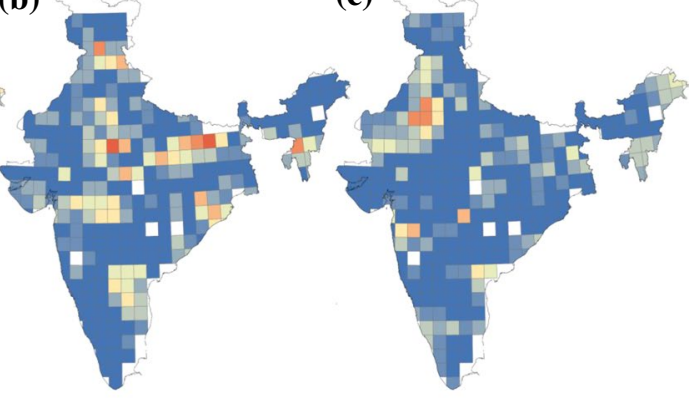

$0.0-0.08$

$0.08-0.16$

$0.16-0.24$

$0.24-0.32$

$0.32-0.40$

$0.40-0.50$

$0.50-0.60$

$0.60-0.70$

$0.70-0.80$

$0.80-0.87$

Fig. 4 Variation partitioning showing the individual effect of anomaly on invasive species a temperature and precipitation, $\mathbf{b}$ temperature only, $\mathbf{c}$ precipitation only 
dominant over Rajasthan and Punjab states of semi-arid and desert zone showing more than $35 \%$ of variation individually (Fig. 4c). Spatially the combination of both anomalies showed improvement in spatial variation compared to the individual variable.

\section{Discussion}

The influence of climate anomaly as a representative of past climate could be used to reveal the future distribution of invasive species. In this study, the better correlation of invasive species with both the anomalies i.e. temperature and precipitation anomaly reveals the affinity of invasive species towards warmer, drier and wet places, which also gives an indication of the adaptive capability of them to a broad bioclimatic envelop. We observed the distribution of invasive species in the regions where precipitation and temperature have increased during the last 100 years (Fig. 2). In addition, moderate to a higher number of invasive species also occupied the drier regions.

The higher number of invasive species in arid and semi-arid zones could be attributed to the drier conditions as revealed by the variation partitioning which shows a better correlation of invasive species with precipitation anomaly. In addition, an increase in mean temperature during the past 100 years could have exaggerated the drier conditions in the zone.

The arid and semi-arid zones of India can be considered as low resource regions. The low resource environments are severely limited by light, nutrient and water. Availability of water is an important factor for plant growth, development and distribution. As a general hypothesis, native species outperform invasive species under low resource availability (Ashbacher and Cleland 2015). In arid regions plants can increase water use efficiency (WUE) and reduce transpiration loss which leads the native species to successfully compete against invasive species. However, studies have contradicted the above findings that under low resource conditions invasive species can persist due to various traits which enables them to maximise the resource use efficiency. Funk and Vitousek (2007) observed that invasive species were more efficient than native species at using limited resources on short time scales in Hawaii. Cleverly et al. (1997) observed that invasive species tamarix possesses similar leaf level transpiration rate and sap flow as the native species. These results reveal the functionality of invasive species at lower water potential with high water retention as a consequence of its ability to utilize unsaturated soil moisture which helps to avoid damage to photosynthetic apparatus in the driest regions. Thus, indicating that invasive species might have physiological traits making them more tolerant to stress as compared to native species (Cleverly et al. 1997).

In the humid regions of the lower Deccan peninsula (Eastern Ghats of India), our results showed an increase in temperature and precipitation anomaly and their good correlation with invasive species. This can be understood by the fact that longer growing season gives an advantage to the species, as it enables the Invasive species to initiate their growth and reproduction under available resources those are able to initiate their growth and reproduce under available resources (i.e. water). The interaction of invasive species' flexibility towards the phenological events and vacant niches can be led by climate change. Increase in mean temperature escalates the growing season length, therefore, making many vacant niches (especially at the start and end of the growing season) to be available for species that can successfully adjust. Studies have shown earlier leaves development in the invasive species compared to natives which allow them to use resources by earlier activation through enhanced competitive ability (Wolkovich and Cleland 2011). Wolkovich et al. (2013) observed a shift in the flowering 
of invasive species by tracking of inter-annual variation in temperature of North American mesic systems. Han et al. (2012) observed faster growth of invasive grass species than native species in Australia showing significant correlation with their functionality and phenology. Increased water availability allows plants to maintain high photosynthetic rates for a longer period. However, a negative response can also be observed due to the switchable effect. For example, studies show an increased invasion due to enhanced rainfall patterns (Wu et al. 2010; Ashbacher and Cleland 2015) in contrast, invasions under enhanced rainfall were constrained by soil nutrients and competition in another study by Eskelinen and Harrison (2014). In India, Pergl et al. (2017) observed the occurrence of naturalized invasive species richness is positively related to the states having a comparatively higher amount of precipitation. This implicates precipitation as one of the key climatic factor shaping the richness of regional invasive species in India.

The low number of invasive species in the Himalayan region and Gangetic plains could be attributed to low sampling. We observed a clear contrast to literature where invasive species expansion is supported by disturbances (Gelbard and Belnap 2003; Domenech et al. 2005; Bradley and Mustard 2006). In general, disturbance makes resources available providing opportunities for invasive species to prosper by forming "corridors". These corridors act as invasion outlets into both fragmented and undisturbed landscapes. For example, resources like light intensity and below ground nutrients can be available to invasive species due to deforestation. However, low species in the Gangetic plain zone could be attributed to the project protocol which only focuses on the sampling of vegetation types and due to very less forested areas in the Gangetic plains exhausted sampling was not carried out (Tripathi et al. 2017). A very low number of invasive species c.a. 0-10 were observed in the Himalayan regions of India. This is in contrast with another study by Khuroo et al. (2007) where they observed nearly 571 invasive species solely in Kashmir Himalaya. The grids in the Himalayan region suffered from under-sampling due to inaccessibility (Tripathi et al 2017). This region spans over an elevation range of above $100 \mathrm{~m}$ to 5000 showing maximum deviation (nearly $1000 \mathrm{~m}$ ) at $1^{\circ}$ with an average temperature of c.a. $8-10^{\circ} \mathrm{C}$. This punitive climate limits the accessibility of inventor to sample the region.

Apart from climate, anthropogenic activities have been argued to facilitate species invasion (Tilman and Lehma 2001; Zimmermann et al. 2014). In India, Adhikari et al. (2015) identified invasion hotspots containing the diverse signature of human activities, and are characterized by 5 major anthropogenic biome types and 18 sub-types. Kosaka et al. (2010) suggested that recent construction and use of roads assists the establishment of invasive alien plants in the Himalayan region of Arunachal Pradesh. In addition, the use of edaphic predictors significantly affects the model performance and enhances the accuracy compared to those constructed only with climate variables Velazco et al. (2017). For example, Bansal et al. (2014) observed that variation in soil properties such as clay content, $\mathrm{pH}$ and soil $\mathrm{N}$ correlated with a two to four-fold change in plant growth of invasive grasses at Northern Great Basin, western USA. Therefore, the use of other predictor variables (i.e. edaphic and anthropogenic) would enhance model performance and could be an inclusive input in a future perspective.

\section{Conclusion}

Our results show climate anomaly variables will influence the establishment of invasive species but the effect should be expected to species-specific. This study has revealed the spatial variation in the invasive plant species distribution co-vary with climate anomalies. 
This suggests that local models could be used to see the interaction of invasive plant species w.r.t. climate anomalies and other predictor variables since the global model might make erroneous predictions and mask the influence of spatial variation due to heterogeneity at varying neighbour distances. Although the data used here to show anomaly relationship is limited due to various constraints, we strongly believe that it gives insights of climate anomaly effects on invasion. This could be a preliminary step and future studies may be recommended to monitor \& get more insights of invasive species behaviour towards climate change on temporal basis.

Disclaimer The views and interpretations in this publication are those of the authors and are not necessarily attributable to ICIMOD.

\section{References}

Adhikari D, Tiwary R, Barik SK (2015) Modelling hotspots for invasive alien plants in India. PLoS ONE 10(7):e0134665

Ashbacher AC, Cleland EE (2015) Native and exotic plant species show differential growth but similar functional trait responses to experimental rainfall. Ecosphere 6(11):1-4

Asner GP, Martin RE, Carlson KM, Rascher U, Vitousek PM (2006) Vegetation-climate interactions among native and invasive species in Hawaiian rainforest. Ecosystems 9(7):1106-1117

Baker HG (1965) Characteristics and modes of origin of weeds. Characteristics and modes of origin of weeds. Academic Press, New York, pp 147-172

Baker HG (1974) The evolution of weeds. Annu Rev Ecol Syst 5(1):1-24

Banerjee S, Carlin BP, Gelfand AE (2004) Hierarchical analysis and modeling for spatial data. Chapman and HallCRC, Boca Raton

Bansal S, James JJ, Sheley RL (2014) The effects of precipitation and soil type on three invasive annual grasses in the western United States. J Arid Environ 104:38-42

Barik SK, Adhikari D (2012) Predicting the geographical distribution of an invasive species (Chromolaena odorata L. (King) \& HE Robins) in the Indian subcontinent under climate change scenarios. Invasive alien plants: an ecological appraisal for the Indian subcontinent, pp 77-88

Beale CM, Lennon JJ, Elston DA, Brewer MJ, Yearsley JM (2007) Red herrings remain in geographical ecology: a reply to Hawkins et al. (2007). Echography 30(6):845-847

Bradley BA, Mustard JF (2006) Characterizing the landscape dynamics of an invasive plant and risk of invasion using remote sensing. Ecol Appl 16(3):1132-1147

Cleverly JR, Smith SD, Sala A, Devitt DA (1997) Invasive capacity of Tamarix ramosissima in a Mojave Desert floodplain: the role of drought. Oecologia 111(1):12-18

Compagnoni A, Adler PB (2014) Warming, competition, and Bromus tectorum population growth across an elevation gradient. Ecosphere 5(9):1-34

Cox JR, Ruyle GB (1986) Influence of climatic and edaphic factors on the distribution of Eragrostis lehmanniana Nees in Arizona, USA. J Grassl Soc Southern Afr 3(1):25-29

Dogra KS, Kohli RK, Sood SK (2009) An assessment and impact of three invasive species in the Shivalik hills of Himachal Pradesh, India. Int J Biodivers Conserv 1(1):4-10

Domenech R, Vila M, Pino J, Gesti J (2005) Historical land-use legacy and Cortaderia selloana invasion in the Mediterranean region. Glob Change Biol 11(7):1054-1064

Easterling DR, Meehl GA, Parmesan C, Changnon SA, Karl TR, Mearns LO (2000) Climate extremes: observations, modeling, and impacts. Science 289(5487):2068-2074

Eiserhardt WL, Bjorholm S, Svenning JC, Rangel TF, Balslev H (2011) Testing the water-energy theory on American palms (Arecaceae) using geographically weighted regression. PLoS ONE 6(11):e27027

Eskelinen A, Harrison S (2014) Exotic plant invasions under enhanced rainfall are constrained by soil nutrients and competition. Ecology 95(3):682-692

Fotheringham AS, Brunsdon C, Charlton M (2002) Geographically weighted regression: the analysis of spatially varying relationships. Wiley, Chichester

Funk JL, Vitousek PM (2007) Resource-use efficiency and plant invasion in low-resource systems. Nature 446(7139):1079 
Gao J, Li S, Zhao Z, Cai Y (2012) Investigating spatial variation in the relationships between NDVI and environmental factors at multi-scales: a case study of Guizhou Karst Plateau, China. Int J Remote Sens 33(7):2112-2129

Gelbard JL, Belnap J (2003) Roads as conduits for exotic plant invasions in a semiarid landscape. Conserv Biol 17(2):420-432

Han Y, Buckley YM, Firn J (2012) An invasive grass shows colonization advantages over native grasses under conditions of low resource availability. Plant Ecol 213(7):1117-1130

Hellmann JJ, Byers JE, Bierwagen BG, Dukes JS (2008) Five potential consequences of climate change for invasive species. Conserv Biol 22(3):534-543

Inderjit S (ed) (2005) Invasive plants: ecological and agricultural aspects. Springer, Berlin

Inderjit PJ, van Kleunen M, Hejda M, Babu CR, Majumdar S, Singh P, Singh SP, Salamma S, Rao BRP, Pyšek P (2017) Naturalized alien flora of the Indian states: biogeographic patterns, taxonomic structure and drivers of species richness. Biol Invasions 20(6):1625-1638

IndianStat (2017) Formatted numbers of India. Galitein Technologies, Gujarat. http://www.indianstat.in. Accessed 2016

Kannan R, Shackleton CM, Shaanker RU (2013) Reconstructing the history of introduction and spread of the invasive species, Lantana, at three spatial scales in India. Biol Invasions 15(6):1287-1302

Kawale J, Chatterjee S, Kumar A, Liess S, Steinbach M, Kumar V (2011) Anomaly construction in climate data: issues and challenges. In: NASA conference on intelligent data understanding, CIDU, pp 189-203

Khuroo AA, Rashid I, Reshi Z, Dar GH, Wafai BA (2007) The alien flora of Kashmir Himalaya. Biol Invasions 9(3):269-292

Khuroo AA, Reshi ZA, Malik AH, Weber E, Rashid I, Dar GH (2012) Alien flora of India: taxonomic composition, invasion status and biogeographic affiliations. Biol Invasions 14(1):99-113

Kimball S, Gremer JR, Barron-Gafford GA, Angert AL, Huxman TE, Venable DL (2014) High water-use efficiency and growth contribute to success of non-native Erodium cicutarium in a Sonoran Desert winter annual community. Conserv Physiol. https://doi.org/10.1093/conphys/cou006

Kohli RK, Dogra KS, Batish DR, Singh HP (2004) Impact of invasive plants on the structure and composition of natural vegetation of northwestern Indian Himalayas. Weed Technol 18(1):1296-1300

Kolar CS, Lodge DM (2001) Progress in invasion biology: predicting invaders. Trends Ecol Evol 16(4):199-204

Kosaka Y, Saikia B, Mingki T, Tag H, Riba T, Ando K (2010) Roadside distribution patterns of invasive alien plants along an altitudinal gradient in Arunachal Himalaya, India. Mt Res Dev 30(3):252-258

Kumschick S, Bacher S, Evans T, Markova’ Z, Pergl J, Pys`ek P, Vaes-Petignat S, van der Veer G, Vila` M, Nentwig W (2015) Comparing impacts of alien plants and animals using a standard scoring system. J Appl Ecol 52:552-561

Latimer AM, Banerjee S, Sang H Jr, Mosher ES, Silander JA Jr (2009) Hierarchical models facilitate spatial analysis of large data sets: a case study on invasive plant species in the northeastern United States. Ecol Lett 12(2):144-154

Maclean IMD, Wilson RJ (2012) Recent ecological responses to climate change support predictions of high extinction risk. PNAS 108:12337-12342

Majumdar RB, Karthikeyan S (1989) Flora Indicae, Enumeratio Monocotyledonae. Botanical Survey of India, Calcutta, pp 274-283

Martín-Queller E, Gil-Tena A, Saura S (2011) Species richness of woody plants in the landscapes of Central Spain: the role of management disturbances, environment and non-stationarity. J Veg Sci 22(2):238-250

Mitchell TD, Jones PD (2005) An improved method of constructing a database of monthly climate observations and associated high-resolution grids. Int J Climatol 25(6):693-671

Nagar PS, Pathak SJ, Pandya SM (2004) The alien flora of the Barda hills and its surroundings in Gujarat, India. Indian J For 27:25-38

Nentwig W (ed) (2007) Biological invasions, vol 193. Springer, Berlin

New M, Hulme M, Jones P (1999) Representing twentieth-century space-time climate variability. Part I: development of a 1961-90 mean monthly terrestrial climatology. J Clim 12(3):829-856

Panda RM, Behera MD, Roy PS (2018) Assessing distributions of two invasive species of contrasting habits in future climate. J Environ Manag 213:478-488

Pandey RP, Parmar PJ (1994) The exotic flora of Rajasthan. J Econ Taxon Bot 18(1):105-136

Pantoja PO, Paine CT, Vallejo-Marín M (2018) Natural selection and outbreeding depression suggest adaptive differentiation in the invasive range of a clonal plant. Proc R Soc B 285(1882):20181091 
Pergl J, van Kleunen M, Hejda M, Babu CR, Majumdar S, Singh P, Singh SP, Salamma S, Rao BRP, Pyšek P (2017) Naturalized alien flora of the Indian states: biogeographic patterns, taxonomic structure and drivers of species richness. Biol Invasions 20(6):1625-1638

Pyšek P, Richardson DM (2010) Invasive species, environmental change and management, and health. Ann Rev Environ Resour 35:25-55

Rangel TF, Diniz-Filho JA, Bini LM (2010) SAM: a comprehensive application for spatial analysis in macroecology. Ecography 33(1):46-50

Richardson DM, Bond WJ, Dean WR, Higgins SI, Midgley GF, Milton SJ, Powrie LW, Rutherford MC, Samways MJ, Schulze RE (2000) Invasive alien species and global change: a South African perspective. Invasive species in a changing world, pp 303-349

Rodgers WA, Panwar HS (1988) Planning a wildlife protected area network in India. A report for the ministry of Environment and forests and wildlife, Government of India, vol $1 \& 2$

Rosenzweig C, Iglesias A, Yang XB, Epstein PR, Chivian E (2000) Climate change and US agriculture: the impacts of warming and extreme weather events on productivity, plant diseases, and pests. Center for Health and the Global Environment, Harvard Medical School, Boston

Roy PS, Behera MD, Murthy MS, Roy A, Singh S, Kushwaha SP, Jha CS, Sudhakar S, Joshi PK, Reddy CS et al (2015) New vegetation type map of India prepared using satellite remote sensing: comparison with global vegetation maps and utilities. Int J Appl Earth Observ Geoinform 39:142-159

Rumlerova`Z, Vila` M, Pergl J, Nentwig W, Pys`ek P (2016) Scoring environmental and socioeconomic impacts of alien plants invasive in Europe. Biol Invasions 18:3697-3711

Sajeev TV, Sankaran KV, Suresh TA (2012) Are alien invasive plants a threat to forests of Kerala?. KFRI occasional papers, Forest Health Programme Division. Kerala Forest Research Institute, Peechi

Seastedt TR, Pyšek P (2011) Mechanisms of plant invasions of North American and European grasslands. Annu Rev Ecol Evol Syst 42(1):133

Sharma BD, Pandey DS (1984) Exotic flora of Allahabad District. Bot Surv India, Kolkata

Sharma GP, Singh JS, Raghuvanshi AS (2005) Plant invasions: emerging trends and future implications. Curr Sci 88:726-734

Shrestha PM (2006) Comparison of ordinary least square regression, spatial autoregression, and geographically weighted regression for modeling forest structural attributes using a geographical information system (GIS)/remote sensing (RS) approach. PhD Thesis. University of Calgary

Smith AL, Hewitt N, Klenk N, Bazley DR, Norman Y et al (2012) Effects of climate change on the distribution of invasive alien species in Canada: a knowledge synthesis of range change projections in a warming world. Environ Rev 20:1-16

Thapa S, Chitale V, Rijal SJ, Bisht N, Shrestha BB (2018) Understanding the dynamics in distribution of invasive alien plant species under predicted climate change in Western Himalaya. PLoS ONE 13(4):e0195752

Tilman D, Lehman C (2001) Human-caused environmental change: impacts on plant diversity and evolution. Proc Natl Acad Sci 98(10):5433-5440

Tripathi P, Behera MD, Roy PS (2017) Optimized grid representation of plant species richness in India-utility of an existing national database in integrated ecological analysis. PLoS ONE 12(3):e0173774

Velazco SJE, Galvão F, Villalobos F, Júnior PDM (2017) Using worldwide edaphic data to model plant species niches: an assessment at a continental extent. PLoS ONE 12(10):e0186025

Visser ME (2008) Keeping up with a warming world; assessing the rate of adaptation to climate change. Proc R Soc Lond B 275(1635):649-659

Vitousek PM, D’Antonio CM, Loope LL, Westbrooks R (1996) Biological invasions as global environmental change. Am Sci 84(5):468-478

Walther GR, Roques A, Hulme PE, Sykes MT, Pysek P, Kuhn I, Zobel M, Bacher S, Botta-Dukat Z, Bugmann H, Czucz B, Dauber J, Hickler T, Jarosik V, Kenis M, Klotz S, Minchin D, Moora M, Nentwig W, Ott J, Panov VE, Reineking B, Robinet C, Semenchenko V, Solarz W, Thuiller W, Vila M, Vohland K, Settele J (2009) Alien species in a warmer world: risks and opportunities. Trends Ecol Evol 24(12):686-693

White T, Campbell BD, Kemp PD, Hunt CL (2001) Impacts of extreme climatic events on competition during grassland invasions. Glob Change Biol 7(1):1-13

Wolkovich EM, Cleland EE (2011) The phenology of plant invasions: a community ecology perspective. Front Ecol Environ 9(5):287-294

Wolkovich EM, Davies TJ, Schaefer H, Cleland EE, Cook BI, Travers SE, Willis CG, Davis CC (2013) Temperature-dependent shifts in phenology contribute to the success of exotic species with climate change. Am J Bot 100(7):1407-1421 
Wu SH, Sun HT, Teng YC, Rejmánek M, Chaw SM, Yang TY, Hsieh CF (2010) Patterns of plant invasions in China: taxonomic, biogeographic, climatic approaches and anthropogenic effects. Biol Invasions 12(7):2179-2206

Xu X, Wang Z, Rahbek C, Sanders NJ, Fang J (2016) Geographical variation in the importance of water and energy for oak diversity. J Biogeogr 43(2):279-288

Zhao Z, Gao J, Wang Y, Liu J, Li S (2015) Exploring spatially variable relationships between NDVI and climatic factors in a transition zone using geographically weighted regression. Theor Appl Climatol 120(3-4):507-519

Zimmermann H, Brandt P, Fischer J, Welk E, von Wehrden H (2014) The human release hypothesis for biological invasions: human activity as a determinant of the abundance of invasive plant species. F1000Research. https://doi.org/10.12688/f1000research.3740.2

Publisher's Note Springer Nature remains neutral with regard to jurisdictional claims in published maps and institutional affiliations.

\section{Affiliations}

\section{Poonam Tripathi ${ }^{1,2} \cdot$ Mukunda Dev Behera $^{2} \cdot$ Partha Sarathi Roy $^{3}$}

Poonam Tripathi

tripathy.poonam@gmail.com; Poonam.Tripathi@icimod.org

Mukunda Dev Behera

mukundbehera@gmail.com

Partha Sarathi Roy

R.Parthsarathi@cgiar.org; psroy13@gmail.com

1 International Centre for Integrated Mountain Development, Khumaltar, Lalitpur, G.P.O. Box 3226, Kathmandu, Nepal

2 Centre for Oceans, Rivers, Atmosphere and Land Sciences (CORAL), Indian Institute of Technology Kharagpur, Kharagpur, West Bengal 721302, India

3 System Analysis for Climate Smart Agriculture, Innovation Systems for the Dry Lands, ICRISAT, Patancheru, Hyderabad 502 324, India 